\title{
Thermodynamic and Acoustic Properties of Mixtures of Dibromomethane + Heptane
}

\author{
Anna Przybyła • Mirosław Chorążewski • \\ Edward Zorębski • Wojciech Marczak
}

Received: 30 April 2010 / Accepted: 15 June 2010 / Published online: 4 July 2010

(C) The Author(s) 2010. This article is published with open access at Springerlink.com

\begin{abstract}
Densities and speeds of ultrasound in binary mixtures of dibromomethane with heptane have been measured within the temperature range from $288.15 \mathrm{~K}$ to $318.15 \mathrm{~K}$. From the experimental data, the thermodynamic excess volume, molar isobaric expansion, molar isentropic compression, and ultrasonic speed were calculated. The excess volume and excess isentropic compression have opposite signs, whereas the excess isobaric expansion is an S-shaped function of the mole fraction. An explanation was suggested to account for the excesses in terms of intermolecular interactions. It involved energetic and steric factors. Moreover, it was shown that the positive excess sound speed results almost entirely from the negative excess compression.
\end{abstract}

Keywords Binary mixtures - Dibromomethane - Excess properties $\cdot$ Heptane Speed of sound

\section{Introduction}

Haloalkanes and their mixtures have been commercially used for two centuries. Since the halide atom can be easily substituted by other functional groups, haloalkanes are intermediate products in many chemical reactions of practical importance. For example, dibromomethane may act as a one-carbon source in organic syntheses [1-4]. Halomethanes are used in syntheses of pharmaceuticals, herbicides, and pesticides. They are applied as fumigants and fire extinguishing media [5]. In spite of such

Electronic supplementary material The online version of this article (doi:10.1007/s10765-010-0773-1) contains supplementary material, which is available to authorized users.

\footnotetext{
A. Przybyła (凶) · M. Chorążewski · E. Zorębski · W. Marczak Institute of Chemistry, University of Silesia, Szkolna 9, Katowice 40-006, Poland e-mail: mareintryga@interia.pl
} 
widespread use, there are still gaps in the thermodynamic datasets for haloalkanes and their mixtures. Thus, systematic studies of the single- and multicomponent systems containing dibromoalkanes have been undertaken. For the pure dibromoalkanes, the attention has been focused on the improvement of group contributions for the estimation of heat capacities [6]. Investigations of the 1,5-dibromopentane +heptane and 1,2-dibromoethane + heptane mixtures revealed that the systems were thermodynamically non-ideal [7-9]. That seems a general feature of the haloalkane + alkane systems. The volume effects of mixing of dihaloalkanes and their homomorphic monohydroxy alcohols with hydrocarbons are positive and close to one another $[7,10,11]$. Moreover, large positive excess enthalpies of the mixtures of hexane with a series of $\alpha, \omega$-dibromoalkanes [12-14] suggest strong attractions between the molecules in pure liquids. The interactions in the pure substances and in the mixtures result solely from the permanent and instantaneous electric multipoles, since neither dibromoalkanes nor hydrocarbons are capable of specific interactions. Nevertheless, some effects of mixing are spectacular. For example, the W-shaped excess heat capacities for 1,2-dibromoethane + (hexane or heptane) [7] are similar to those of 1,4-dioxane+alkanes [15], whereas the opposite signs of the excesses of compression and volume [7] are just like those for the mixtures of 1-pentanol with 1-octanol [16].

This study deals with the system dibromomethane + heptane. Dibromomethane, similar to other dihalogenoalkanes, is unstable, sensitive to light and temperature. That is probably a reason why the thermodynamic studies of dibromoalkanes have been rather scarce. To our knowledge, the speeds of sound and densities for dibromomethane + heptane have not been reported yet. Our experimental results cover the whole concentration range and the temperature interval $288.15 \mathrm{~K}$ to $318.15 \mathrm{~K}$. From the experimental data, the excesses of molar volume $\left(V^{\mathrm{E}}\right)$, molar isobaric expansion $\left(E_{p}^{\mathrm{E}}\right)$, molar isentropic compression $\left(K_{S}^{\mathrm{E}}\right)$, and speed of sound $\left(u^{\mathrm{E}}\right)$ were calculated. The results were discussed in terms of intermolecular interactions.

\section{Experimental}

\subsection{Chemicals}

Heptane (POCH, min. 99\%) was used as supplied by the manufacturer. Dibromomethane (Alfa Aesar, >99\%) was purified before use by fractional distillation. The purities of the liquid samples were checked by the comparison of the measured density and refractive index with literature data (Table 1). The agreement is very good for heptane and at least satisfactory for dibromomethane. As was mentioned earlier, dibromomethane is chemically unstable, which accounts for the discrepancies in reported densities and refractive indices. The chemicals were kept in dark glass flasks stored in a desiccator wrapped in aluminum foil.

The mixtures were prepared by mass using an Ohaus AS-200 analytical balance with an accuracy of $\pm 6 \times 10^{-4} \mathrm{~g}$. Before measurements, every sample was degassed in an ultrasonic cleaner (Unitra Unima UM4). The solutions were used immediately after they were prepared. 
Table 1 Densities $\rho$ and refractive indices $n_{\mathrm{D}}$ of dibromomethane and heptane at $T=298.15 \mathrm{~K}$ used in this study and reported in the literature

\begin{tabular}{lll}
\hline Liquid & This work & Literature \\
\hline Dibromomethane & & $n_{\mathrm{D}}$ \\
& \multirow{2}{*}{1.5380} & $1.53674[29] ; 1.5389[35]$ \\
& & $\rho\left(\mathrm{kg} \cdot \mathrm{m}^{-3}\right)$ \\
& 2482.97 & $2477.8[29] ; 2478.36[30] ;$ \\
& $2478.37[31] ; 2480.83[32] ;$ \\
& $2481.5[33] ; 2481.86[9] ;$ \\
& $2483.97[34] ; 2484.2[35]$ \\
Heptane & $n_{\mathrm{D}}$ \\
& $1.3851[36] ; 1.38511[37]$ \\
& $\rho\left(\mathrm{kg} \cdot \mathrm{m}^{-3}\right)$ \\
& & $679.51[37] ; 679.59[7] ;$ \\
& $679.60[38] ; 679.62[39] ;$ \\
& $679.66[40,41] ; 679.68$ \\
& & {$[42] ; 679.69[8] ; 679.75$} \\
& {$[43] ; 679.78[44]$} \\
\hline
\end{tabular}

\subsection{Apparatus}

The densities were measured by a vibrating-tube densimeter (Anton Paar DMA 5000) with an uncertainty of $5 \times 10^{-2} \mathrm{~kg} \cdot \mathrm{m}^{-3}$. The uncertainty was estimated from the results of measurements of the density standards: pure organic liquids and aqueous solutions of salts. Resolution was $1 \times 10^{-3} \mathrm{~kg} \cdot \mathrm{m}^{-3}$, which made it possible to establish the time of the measurement sufficiently short to prevent dibromomethane from disintegrating.

The phase speed of ultrasound at $4 \mathrm{MHz}$ was measured with a pulse-echo-overlap apparatus designed and constructed in our laboratory. The measurement uncertainty was estimated at $0.5 \mathrm{~m} \cdot \mathrm{s}^{-1}$, while the precision was an order of magnitude better [17].

The refractive indices were measured by an Abbe refractometer RL3 (PZO, Poland) with an uncertainty of $4 \times 10^{-4}$. The temperature of refractometer was stabilized by two water thermostats in a cascade arrangement.

The isobaric heat capacities of dibromomethane and heptane were measured with a scanning microcalorimeter (Setaram DSC III). The uncertainty of the measurements was estimated to be $0.15 \%$. Details of the applied procedures and the calibration have been described previously [18].

\section{Results}

The experimental densities $(\rho)$ and speeds of sound $(u)$ are reported in Tables 2 and 3. Their temperature dependencies were approximated by second-order polynomials:

$$
y=\sum_{i=0}^{2} a_{i}(T / \mathrm{K}-293.15)^{i}
$$




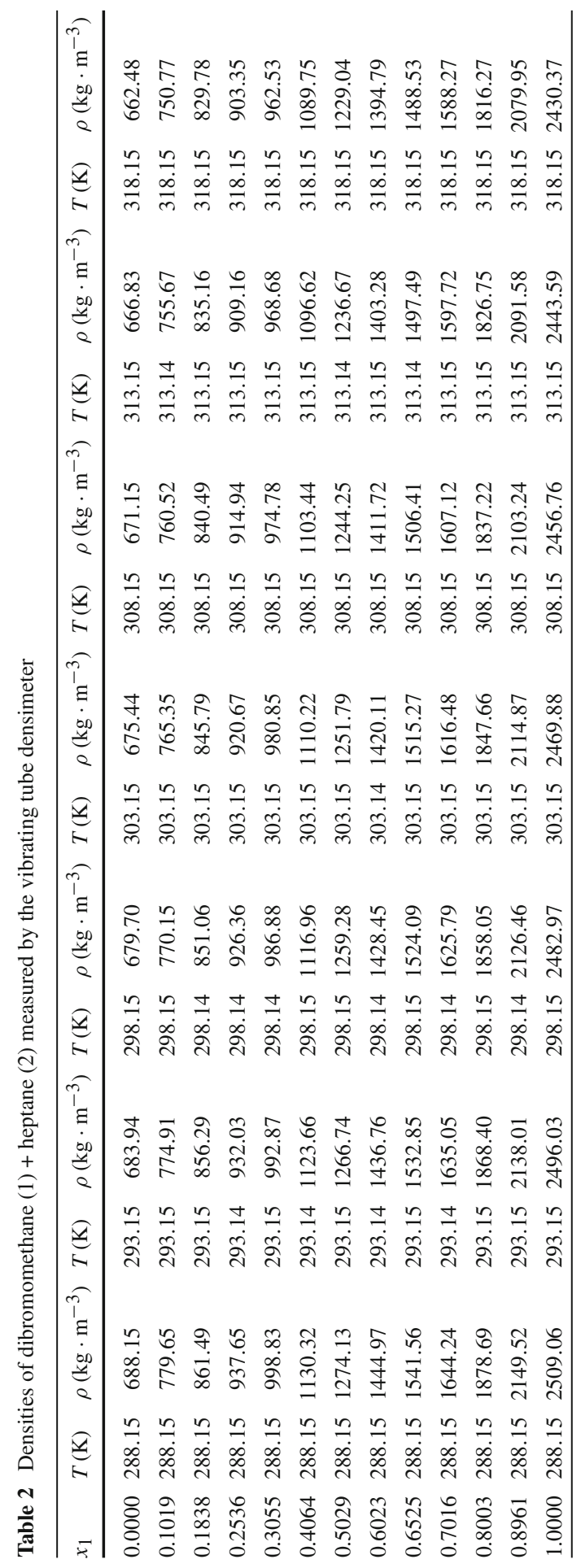




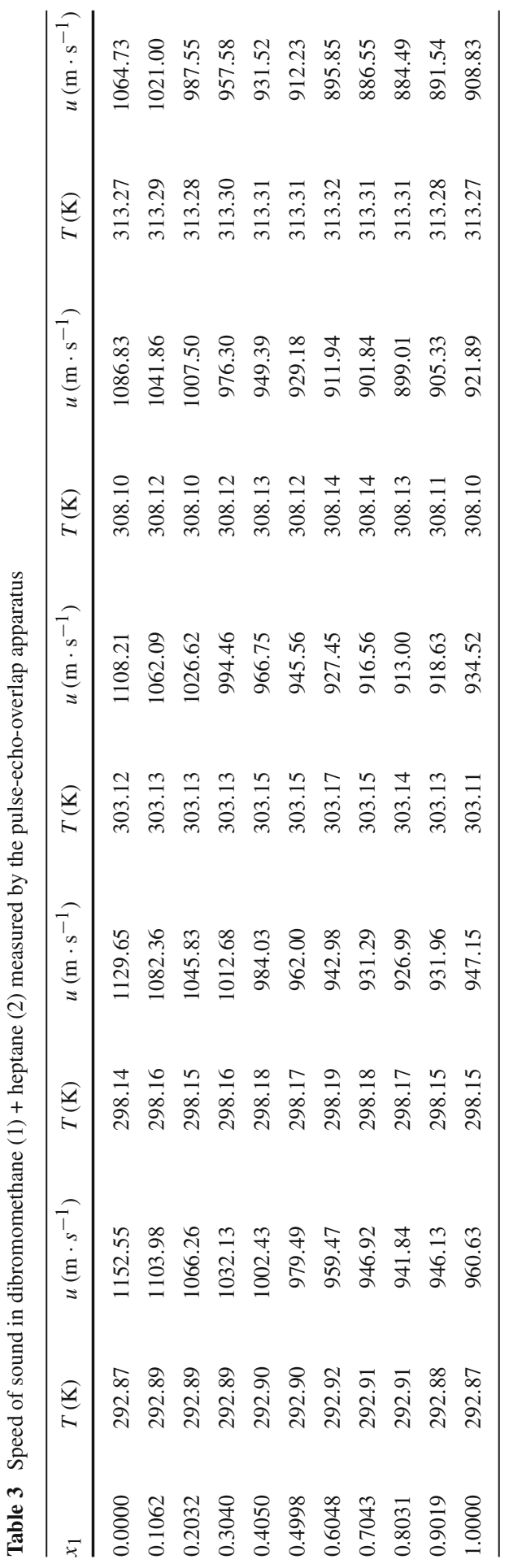


Table 4 Coefficients of the speed of sound, density, and isobaric heat capacity polynomials (Eq. 1) and mean deviations from the regression line $\delta$

\begin{tabular}{|c|c|c|c|c|}
\hline$x_{1}$ & $a_{0}$ & $a_{1}$ & $a_{2} \times 10^{3}$ & $\delta$ \\
\hline \multicolumn{5}{|c|}{ Speed of sound } \\
\hline 0.0000 & $1151.330 \pm 0.009$ & $-4.3506 \pm 0.0020$ & $2.349 \pm 0.096$ & 0.01 \\
\hline 0.1062 & $1102.905 \pm 0.009$ & $-4.1114 \pm 0.0020$ & $2.209 \pm 0.097$ & 0.01 \\
\hline 0.2032 & $1065.221 \pm 0.031$ & $-3.8774 \pm 0.0072$ & $1.015 \pm 0.350$ & 0.03 \\
\hline 0.3040 & $1031.153 \pm 0.010$ & $-3.6997 \pm 0.0023$ & $2.337 \pm 0.110$ & 0.01 \\
\hline 0.4050 & $1001.571 \pm 0.035$ & $-3.4942 \pm 0.0081$ & $0.936 \pm 0.390$ & 0.04 \\
\hline 0.4998 & $978.665 \pm 0.011$ & $-3.3276 \pm 0.0024$ & $1.544 \pm 0.120$ & 0.01 \\
\hline 0.6048 & $958.760 \pm 0.006$ & $-3.1341 \pm 0.0013$ & $0.741 \pm 0.064$ & 0.01 \\
\hline 0.7043 & $946.204 \pm 0.008$ & $-2.9698 \pm 0.0019$ & $0.584 \pm 0.089$ & 0.01 \\
\hline 0.8031 & $941.153 \pm 0.002$ & $-2.8237 \pm 0.0005$ & $0.621 \pm 0.022$ & 0.01 \\
\hline 0.9019 & $945.394 \pm 0.007$ & $-2.6895 \pm 0.0017$ & $0.730 \pm 0.081$ & 0.01 \\
\hline 1.0000 & $959.902 \pm 0.005$ & $-2.5572 \pm 0.0011$ & $0.946 \pm 0.055$ & 0.01 \\
\hline \multicolumn{5}{|l|}{ Density } \\
\hline 0.0000 & $683.938 \pm 0.002$ & $-0.8444 \pm 0.0003$ & $-0.570 \pm 0.012$ & 0.01 \\
\hline 0.1019 & $774.911 \pm 0.002$ & $-0.9501 \pm 0.0003$ & $-0.627 \pm 0.013$ & 0.01 \\
\hline 0.1838 & $856.287 \pm 0.002$ & $-1.0436 \pm 0.0004$ & $-0.661 \pm 0.019$ & 0.01 \\
\hline 0.2536 & $932.023 \pm 0.003$ & $-1.1290 \pm 0.0005$ & $-0.722 \pm 0.023$ & 0.01 \\
\hline 0.3055 & $992.871 \pm 0.002$ & $-1.1955 \pm 0.0004$ & $-0.732 \pm 0.016$ & 0.01 \\
\hline 0.4064 & $1123.658 \pm 0.002$ & $-1.3365 \pm 0.0003$ & $-0.805 \pm 0.015$ & 0.01 \\
\hline 0.5029 & $1266.726 \pm 0.001$ & $-1.4854 \pm 0.0002$ & $-0.888 \pm 0.010$ & 0.01 \\
\hline 0.6023 & $1436.734 \pm 0.004$ & $-1.6529 \pm 0.0007$ & $-1.007 \pm 0.031$ & 0.01 \\
\hline 0.6525 & $1532.842 \pm 0.002$ & $-1.7485 \pm 0.0003$ & $-0.974 \pm 0.013$ & 0.01 \\
\hline 0.7016 & $1635.033 \pm 0.002$ & $-1.8465 \pm 0.0004$ & $-0.983 \pm 0.017$ & 0.01 \\
\hline 0.8003 & $1868.383 \pm 0.006$ & $-2.0659 \pm 0.0010$ & $-0.784 \pm 0.046$ & 0.01 \\
\hline 0.8961 & $2137.997 \pm 0.011$ & $-2.3089 \pm 0.0019$ & $-0.562 \pm 0.085$ & 0.02 \\
\hline 1.0000 & $2496.023 \pm 0.003$ & $-2.6081 \pm 0.0006$ & $-0.719 \pm 0.025$ & 0.01 \\
\hline \multicolumn{5}{|c|}{ Heat capacity } \\
\hline 0.0000 & $222.867 \pm 0.006$ & $0.3673 \pm 0.0013$ & $0.744 \pm 0.056$ & 0.18 \\
\hline 1.0000 & $104.805 \pm 0.002$ & $0.0127 \pm 0.0005$ & $0.284 \pm 0.021$ & 0.06 \\
\hline
\end{tabular}

where $y=\rho /\left(\mathrm{kg} \cdot \mathrm{m}^{-3}\right)$ or $y=u /\left(\mathrm{m} \cdot \mathrm{s}^{-1}\right), T$ is the absolute temperature in $\mathrm{K}$, and $a_{i}$ 's are the polynomial coefficients found by the least-squares method and collected in Table 4. The mean deviations from the regression line were smaller than the measurement uncertainty. Thus, in the further calculations, the speeds and densities obtained from Eq. 1 were used rather than the raw experimental data. That procedure makes it possible to get speeds and densities at any temperature within the interval studied.

Similarly as the speed and density, the experimental heat capacities of dibromomethane and heptane in the temperature range from $293.15 \mathrm{~K}$ to $313.15 \mathrm{~K}$ were almost perfectly approximated by Eq. 1 . The regression coefficients for $y=C_{p} /\left(\mathrm{J} \cdot \mathrm{mol}^{-1} \cdot \mathrm{K}^{-1}\right)$ 
are also given in Table 4. Since the heat capacities calculated from Eq. 1 are equal to the experimental values within the measurement uncertainty interval, no raw results have been reported.

From the densities given by Eq. 1, the molar volumes were calculated:

$$
V=M / \rho,
$$

where the molar mass $M=M_{1} x_{1}+M_{2} x_{2}, x$ is the mole fraction, and subscripts 1 and 2 stand for dibromomethane and heptane, respectively. The molar isobaric expansions, $E_{p} \equiv(\partial V / \partial T)_{p}$, were calculated by differentiation of Eq. 1:

$$
E_{p}=-M / \rho^{2}(\partial \rho / \partial T)_{p}
$$

To obtain the molar isentropic compression, $K_{S} \equiv-(\partial V / \partial p)_{S}$, the re-arranged Newton-Laplace formula was used:

$$
K_{S}=V^{2} /\left(M u^{2}\right)
$$

The above equation combines data obtained from the two experiments. Since the concentrations of the mixtures in the density and speed measurements were not the same, the interpolated values of the molar volumes were used. The interpolation consisted in fitting the Redlich-Kister polynomials to the excess volumes $V^{\mathrm{E}}$ in a way described in the following paragraphs.

The thermodynamic excesses were calculated from the definition:

$$
Y^{\mathrm{E}}=Y-Y^{\mathrm{id}}
$$

where $Y$ denotes $V, E_{p}$, or $K_{S}$, and the superscript "id" stands for the ideal mixture. The ideal values were calculated from the thermodynamically exact formulas, i.e.,

$$
K_{S}^{\mathrm{id}}=K_{T}^{\mathrm{id}}-\frac{T\left(E_{p}^{\mathrm{id}}\right)^{2}}{C_{p}^{\mathrm{id}}},
$$

and

$$
Y^{\mathrm{id}}=x_{1} Y_{1}^{*}+x_{2} Y_{2}^{*}
$$

for $Y=V, K_{T}, E_{p}$, and $C_{p}$; the asterisk denotes pure substance (dibromomethane or heptane), $C_{p}$ is the molar isobaric heat capacity, and $K_{T} \equiv-(\partial V / \partial p)_{T}$ is the molar isothermal compression. The molar isothermal compressions of the pure substances were obtained from the isentropic ones:

$$
K_{T, i}^{*}=K_{S, i}^{*}+\frac{T\left(E_{p, i}^{*}\right)^{2}}{C_{p, i}^{*}},
$$


where $i=1$ for dibromomethane and $i=2$ for heptane. The excesses of molar volume and molar isentropic compression are reported in Electronic Supplementary Material.

The excesses of molar volume, isobaric expansion, and isentropic compression were approximated by Redlich-Kister polynomials:

$$
Y^{\mathrm{E}}=x_{1}\left(1-x_{1}\right) \sum_{i} a_{i}\left(1-2 x_{1}\right)^{i},
$$

where $a_{i}$ 's are the regression coefficients, calculated by the least-squares method and $t$-tested to remove the superfluous ones, i.e., those statistically equal to zero. The excesses are plotted in Figs. 1-3 and the $a_{i}$ coefficients are reported in Table 5.

Moreover, the excess speeds of sound were calculated:

$$
u^{\mathrm{E}}=u-u^{\mathrm{id}}=u-V^{\mathrm{id}}\left(M K_{S}^{\mathrm{id}}\right)^{-1 / 2} .
$$

Similar to the previous equations, Eq. 10 is thermodynamically correct. It should be stressed that the "excess speed" fundamentally differs from the conventional thermodynamic excesses, because the speed of sound is an intensive property rather than an extensive one, and it has no extensive counterpart. However, in the excess speeds the compressibility and volume effects of the thermodynamic non-ideality are involved. Thus, the excess speed makes it possible to study the influence of those two factors on the speed in a real mixture. The thermodynamic approach to the molecular acoustic problems seems very promising. Recently, partial and apparent speeds of sound in binary mixtures were defined and discussed [19].

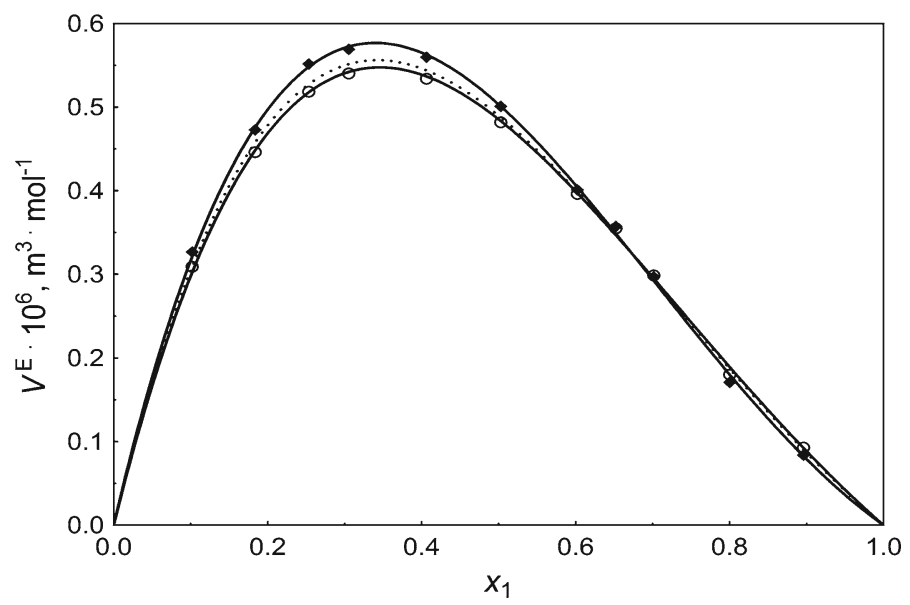

Fig. 1 Excess molar volumes $V^{\mathrm{E}}$ of the dibromomethane (1) + heptane (2) system as a function of mole fraction: points — experimental results: $288.15 \mathrm{~K}$ (open circle); $318.15 \mathrm{~K}$ (filled diamond); lines—RedlichKister polynomials (Eq. 9); dotted line: $298.15 \mathrm{~K}$ (points were omitted for picture clarity) 


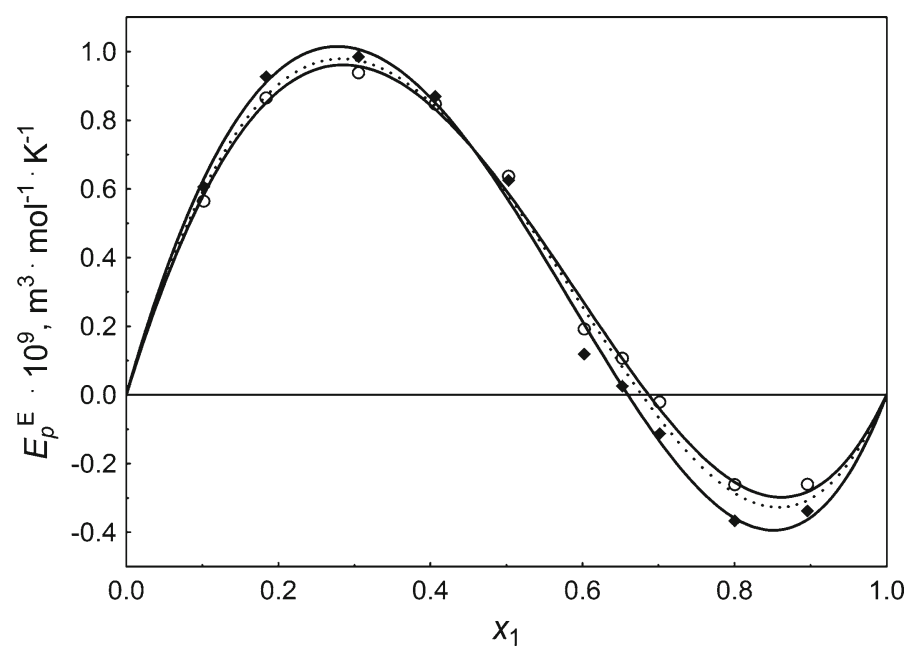

Fig. 2 Excess molar isobaric expansion $E_{p}^{\mathrm{E}}$ of the dibromomethane (1) + heptane (2) system as a function of mole fraction: points-experimental results: $288.15 \mathrm{~K}$ (open circle); $318.15 \mathrm{~K}$ (filled diamond); lines-Redlich-Kister polynomials (Eq. 9); dotted line: 298.15 K (points were omitted for picture clarity)

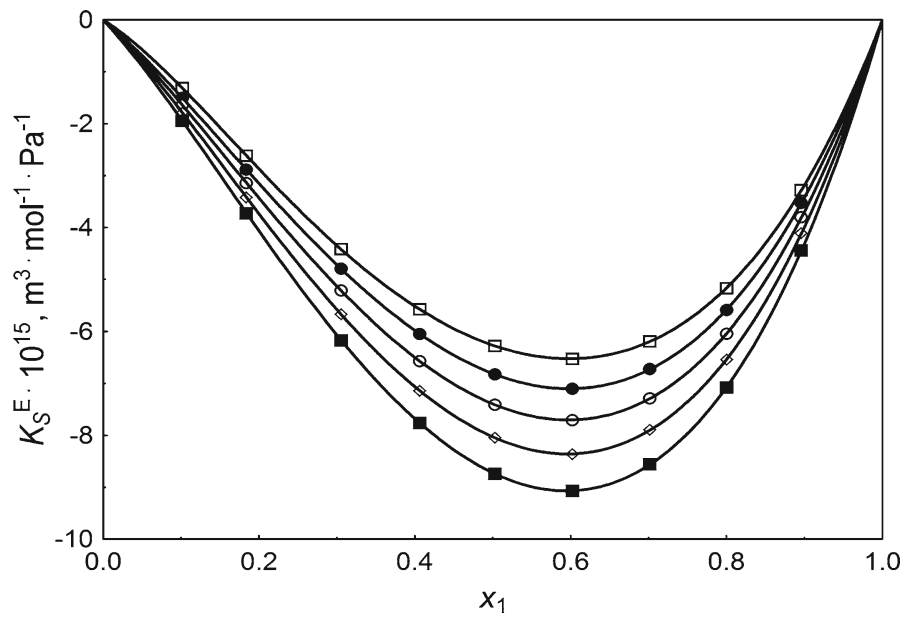

Fig. 3 Excess molar isentropic compression $K_{S}^{\mathrm{E}}$ of the dibromomethane (1) + heptane (2) system as a function of mole fraction: points - experimental results: $293.15 \mathrm{~K}$ (open square); $298.15 \mathrm{~K}$ (filled circle); $303.15 \mathrm{~K}$ (open circle); 308.15 K (open diamond); $313.15 \mathrm{~K}$ (filled square); lines-Redlich-Kister polynomials (Eq. 9)

\section{Discussion and Conclusions}

Excess molar volumes are positive in the whole concentration range (Fig. 1), i.e., the average intermolecular distance in a mixture is longer than that in the corresponding ideal system. That loosened molecular arrangement reflects the changes in the intermolecular interactions caused by substitution of one type of molecules by another. 
Table 5 Coefficients of the Redlich-Kister polynomials (Eq. 9) for the molar excesses of volume, isobaric expansion, and isentropic compression, and mean deviations from the regression lines $\delta$

\begin{tabular}{|c|c|c|c|c|c|}
\hline$T(\mathrm{~K})$ & $a_{0}$ & $a_{1}$ & $a_{2}$ & $a_{3}$ & $\delta$ \\
\hline \multicolumn{6}{|c|}{$V^{\mathrm{E}} \times 10^{6}\left(\mathrm{~m}^{3} \cdot \mathrm{mol}^{-1}\right)$} \\
\hline 288.15 & $1.942 \pm 0.010$ & $1.454 \pm 0.020$ & $0.320 \pm 0.050$ & & 0.005 \\
\hline 293.15 & $1.950 \pm 0.010$ & $1.483 \pm 0.019$ & $0.329 \pm 0.047$ & & 0.005 \\
\hline 298.15 & $1.960 \pm 0.010$ & $1.514 \pm 0.019$ & $0.331 \pm 0.047$ & & 0.005 \\
\hline 303.15 & $1.971 \pm 0.010$ & $1.546 \pm 0.019$ & $0.331 \pm 0.047$ & & 0.005 \\
\hline 308.15 & $1.984 \pm 0.010$ & $1.580 \pm 0.019$ & $0.323 \pm 0.048$ & & 0.005 \\
\hline 313.15 & $1.998 \pm 0.010$ & $1.614 \pm 0.020$ & $0.309 \pm 0.049$ & & 0.005 \\
\hline 318.15 & $2.013 \pm 0.011$ & $1.650 \pm 0.021$ & $0.288 \pm 0.052$ & & 0.005 \\
\hline \multicolumn{6}{|c|}{$E_{p}^{\mathrm{E}} \times 10^{9}\left(\mathrm{~m}^{3} \cdot \mathrm{mol}^{-1} \cdot \mathrm{K}^{-1}\right)$} \\
\hline 288.15 & $2.38 \pm 0.07$ & $5.93 \pm 0.15$ & $-1.13 \pm 0.35$ & & 0.03 \\
\hline 293.15 & $2.37 \pm 0.08$ & $6.06 \pm 0.15$ & $-1.16 \pm 0.36$ & & 0.04 \\
\hline 298.15 & $2.36 \pm 0.08$ & $6.20 \pm 0.16$ & $-1.19 \pm 0.37$ & & 0.04 \\
\hline 303.15 & $2.35 \pm 0.08$ & $6.34 \pm 0.16$ & $-1.22 \pm 0.38$ & & 0.04 \\
\hline 308.15 & $2.33 \pm 0.08$ & $6.49 \pm 0.17$ & $-1.25 \pm 0.39$ & & 0.04 \\
\hline 313.15 & $2.32 \pm 0.08$ & $6.63 \pm 0.17$ & $-1.28 \pm 0.40$ & & 0.04 \\
\hline 318.15 & $2.30 \pm 0.09$ & $6.79 \pm 0.17$ & $-1.31 \pm 0.41$ & & 0.04 \\
\hline \multicolumn{6}{|c|}{$K_{S}^{\mathrm{E}} \times 10^{15}\left(\mathrm{~m}^{3} \cdot \mathrm{mol}^{-1} \cdot \mathrm{Pa}^{-1}\right)$} \\
\hline 293.15 & $-25.099 \pm 0.044$ & $10.656 \pm 0.18$ & $-0.514 \pm 0.20$ & $3.570 \pm 0.46$ & 0.019 \\
\hline 298.15 & $-27.243 \pm 0.058$ & $11.474 \pm 0.23$ & & $3.689 \pm 0.60$ & 0.025 \\
\hline 303.15 & $-29.578 \pm 0.073$ & $12.335 \pm 0.29$ & & $3.873 \pm 0.76$ & 0.032 \\
\hline 308.15 & $-32.121 \pm 0.089$ & $13.240 \pm 0.35$ & & $4.137 \pm 0.92$ & 0.039 \\
\hline 313.15 & $-34.895 \pm 0.11$ & $14.191 \pm 0.44$ & & $4.494 \pm 1.1$ & 0.048 \\
\hline
\end{tabular}

The attraction energy can be estimated from the well-known formula for two interacting molecules [20]:

$$
V=-C / r^{6}
$$

where $r$ is the intermolecular distance and $C$ is a constant. For the London, Debye, and Keesom interactions, the constants are given by

$$
\begin{aligned}
C_{\mathrm{L}} & =\frac{3}{2} \alpha_{1}^{\prime} \alpha_{2}^{\prime} \frac{I_{1} I_{2}}{I_{1}+I_{2}}, \\
C_{\mathrm{D}} & =\frac{\mu_{1}^{2} \alpha_{2}^{\prime}}{4 \pi \varepsilon_{0}} \\
C_{\mathrm{K}} & =\frac{2 \mu_{1}^{2} \mu_{2}^{2}}{3\left(4 \pi \varepsilon_{0}\right)^{2} k T},
\end{aligned}
$$


Table 6 Polarizability volumes, dipole moments, ionization energies, and the interactions energy coefficients (Eqs. 11-15) for dibromomethane and heptane

\begin{tabular}{lll}
\hline & $\mathrm{CH}_{2} \mathrm{Br}_{2}$ & $\mathrm{C}_{7} \mathrm{H}_{16}$ \\
\hline$\alpha^{\prime}\left(\AA^{3}\right)$ & $8.7^{\mathrm{a}}$ & $13.7^{\mathrm{a}}$ \\
$\mu(\mathrm{D})$ & $1.43^{\mathrm{b}}$ & 0 \\
$I(\mathrm{eV})$ & $10.41 \pm 0.13^{\mathrm{c}}$ & $9.93 \pm 0.10^{\mathrm{c}}$ \\
$C_{\mathrm{L}}\left(\mathrm{eV} \cdot \AA^{6}\right)$ & 261 & 621 \\
$C_{\mathrm{D}}\left(\mathrm{eV} \cdot \AA^{6}\right)$ & 44 & 0 \\
$C_{\mathrm{K}}\left(\mathrm{eV} \cdot \AA^{6}\right)$ & $42^{\mathrm{d}}$ & 0 \\
$C\left(\mathrm{eV} \cdot \AA^{6}\right)$ & 348 & 621 \\
\hline
\end{tabular}

${ }^{a}$ Calculated from the refractive indices and densities reported in this study

${ }^{b}$ Ref. [45]

${ }^{c}$ Ref. [46]

${ }^{\text {d }}$ At $T=298.15 \mathrm{~K}$

and

$$
C=C_{\mathrm{L}}+C_{\mathrm{D}}+C_{\mathrm{K}}
$$

where $\alpha^{\prime}$ is the polarizability volume, $\mu$ is the permanent dipole moment, $I$ is the ionization energy, $\varepsilon_{0}$ is the electric permittivity of vacuum, and $k$ is Boltzmann's constant. Superscripts 1 and 2 denote the interacting molecules. In Table 6, the $\alpha^{\prime}, \mu, I$, and $C$ parameters for dibromomethane and heptane are collected. Although the main share in the attraction forces between the dibromomethane molecules comes from the London interactions $\left(C_{\mathrm{L}} / C=0.75\right)$, it is smaller than that deduced from the thermodynamic properties of iodoalkane + alkane mixtures. In the latter, those interactions contribute at least 0.93 of the excess enthalpy value [21]. For the other functions, the contribution is even larger. However, our estimation deals with pure dibromomethane rather than solutions in a non-polar solvent. For the mixtures, the $C_{\mathrm{L}} / C$ is obviously greater, because the dipolar molecules are diluted in a non-polar solvent. Moreover, substitution of iodine atom for the less polarizable bromine one undoubtedly increases the dispersion energies.

It is evident that the $C$ parameter for dibromoethane is smaller than that for heptane due to the lower polarizability of $\mathrm{CH}_{2} \mathrm{Br}_{2}$. The contributions from permanent dipoles, manifested in $C_{\mathrm{D}}$ and $C_{\mathrm{L}}$, are too small to compensate for that difference. However, both the normal boiling temperatures as well as the standard enthalpies of vaporization are nearly the same for the two compounds: $T_{\text {boil }}=(371.5 \pm 0.3) \mathrm{K}$ [22] and $\Delta_{\mathrm{vap}} H^{\mathrm{o}}=36.66 \mathrm{~kJ} \cdot \mathrm{mol}^{-1}$ [23] for heptane and $T_{\text {boil }}=(370 \pm 1) \mathrm{K}$ [22] and $\Delta_{\text {vap }} H^{\mathrm{o}}=37.03 \mathrm{~kJ} \cdot \mathrm{mol}^{-1}$ [23] for dibromomethane. Thus, an additional factor must contribute to the total attraction forces in dibromomethane. It seems probable that some molecular pattern resembling that of the crystal remains in the liquid phase. In the crystals, the molecules are arranged in such a way that the shortest of the intermolecular contacts is the $\mathrm{H} \cdots \mathrm{Br}$ one, equal to $3.032 \AA$ to $3.066 \AA$ dependently on 


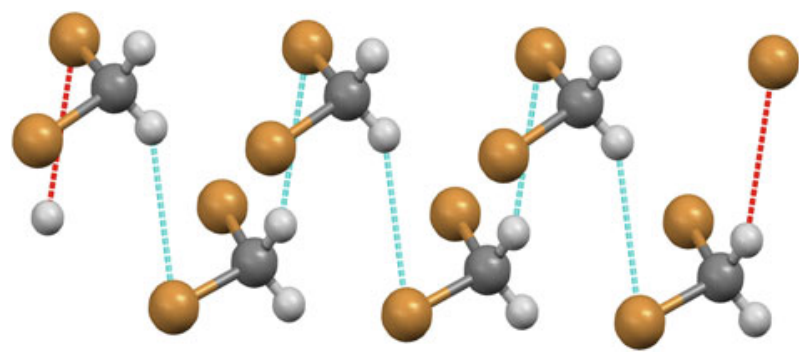

Fig. 4 Nearest-neighboring molecules in the crystal of $\mathrm{CH}_{2} \mathrm{Br}_{2}$. Broken lines mark the shortest distances between the molecules. Picture generated using Mercury 2.3 program from the data reported in the Cambridge Structural Database [28]

temperature and pressure [24]. Since the electrostatic potential is negative along the ring perpendicular to the $\mathrm{C}-\mathrm{Br}$ bond and positive at the both ends beyond $\mathrm{C}$ and $\mathrm{Br}$ atoms [25], the $\mathrm{C}-\mathrm{H}$ and $\mathrm{C}-\mathrm{Br}$ bonds of the nearest-neighboring molecules are nearly perpendicular to one another rather than arranged in a line, while the dipole moments remain parallel (Fig. 4). In the case of the motionless dipoles, the dipole-dipole interaction energy is proportional to the negative third power of the distance rather than to the negative sixth [20]:

$$
V=\frac{\mu_{1} \mu_{2}\left(1-3 \cos ^{2} \theta\right)}{4 \pi \varepsilon_{0} r^{3}},
$$

where $\theta$ is the angle between the dipole axis and the line connecting the two dipoles. For the same intermolecular distance, the energy given by Eq. 16 is higher than the Keesom energy (Eq. 11 with $C=C_{\mathrm{K}}$ ). Moreover, with increasing $r$, the former decreases much slower than the latter.

It seems probable that dilution of dibromomethane by heptane causes that the solvent-separated $\mathrm{CH}_{2} \mathrm{Br}_{2}$ molecules rotate more easily than in the pure solute, which results in a decrease in the total attraction energy larger than that resulting just from the increased $r$. That leads to average molecular distances longer than in the corresponding ideal mixture. Thus, the entropy-driven mixing accounts for the positive excesses of volume and enthalpy. The maximum of the latter equals ca. $1600 \mathrm{~J} \cdot \mathrm{mol}^{-1}$ [12]. With elongation of the alkane chain in the dibromoalkane molecule, the maximum excess decreases to ca. $800 \mathrm{~J} \cdot \mathrm{mol}^{-1}$ for dibromooctane [14]. The decrease is accompanied by a slight shift of the maximum toward lower concentrations of dibromoalkane, from $x_{1}=0.5$ to $x_{1}=0.4$. The volume effect is similar to that observed for the methanol +heptanes system, although smaller as the dipole-dipole interactions are weaker than the hydrogen bonds.

An increase in temperature causes that the excess volume changes as a function of the mixture concentration. It increases at $x_{1}<0.7$ and slightly decreases at $x_{1}>0.7$. A similar effect was observed for 1,2-dibromoethane + heptane [7]. Since the change of the excess volume with temperature is equal to the excess isobaric expansion, $E_{p}^{\mathrm{E}}=\left(\partial V^{\mathrm{E}} / \partial T\right)_{p}$, the temperature dependencies of $V^{\mathrm{E}}$ are characterized by the $E_{p}^{\mathrm{E}}$ functions (Fig. 2) positive at $x_{1}<0.7$ and negative at $x_{1}>0.7$. That 
S-shaped excess expansions reflect the sensitivity of the excess entropy on the changes of pressure, because $E_{p}^{\mathrm{E}}=-\left(\partial S^{\mathrm{E}} / \partial p\right)_{T}$. The excess entropy itself would be positive to compensate the positive excess enthalpy. There seem to be at least two mechanisms that govern the pressure-induced entropy changes. First, the excess entropy may decrease with increasing pressure, $\left(\partial S^{\mathrm{E}} / \partial p\right)_{T}<0$, due to the rotations of molecules gradually obstructed as the intermolecular distance decreases. That would predominate at $x_{1}<0.7$. At higher concentrations, the molecules of dibromomethane are already blocked in their motions due to close contacts of one with another. Thus, another mechanism should be considered. The rotating rod-shaped heptane molecules may break "clusters" of dibromomethane. Consequently, the excess entropy would be larger at higher pressures than at lower ones, and the $\left(\partial S^{\mathrm{E}} / \partial p\right)_{T}>0$ at $x_{1}>0.7$.

Excess molar adiabatic compressions are negative in the whole concentration range (Fig. 3), which indicates that mixtures are stiffer than the corresponding ideal ones. The opposite signs of the $V^{\mathrm{E}}$ and $K_{S}^{\mathrm{E}}$ functions, although uncommon, have already been observed, e.g., for the mixtures of 1-alkanols [16]. As inferred from the positive excess volumes, the intermolecular attraction energies in the mixture seem to be smaller than the averaged energies in its pure components. However, the repulsive interactions are strong enough to cause $K_{S}^{\mathrm{E}}<0$. Similarly as the positive excess volume, the negative excess compression may result from the easier rotations of molecules due to dilution. The molecules of heptane form straight chains that are parallel one to another in the crystals [26], whereas they are randomly arranged in the liquid phase [27]. It seems probable that this randomness increases when dibromomethane molecules get between those of heptane. Spherical dibromomethane molecules may bounce between the heptane chains. Consequently, the freely rotating molecules are difficult to bring one close to another, and that stiffens the mixture.

It seemed instructive to study how the two excesses, that of compression and that of volume, contributed to the excess speed of sound given by Eq. 10. To this end, the latter equation was transformed into the following one:

$$
u^{\mathrm{E}}=\left(V^{\mathrm{id}}+V^{\mathrm{E}}\right)\left[M\left(K_{S}^{\mathrm{id}}+K^{\mathrm{E}}\right)\right]^{-1 / 2}-V^{\mathrm{id}}\left(M K_{S}^{\mathrm{id}}\right)^{-1 / 2},
$$

where $V^{\mathrm{E}}$ and $K_{S}^{\mathrm{E}}$ were calculated from the Redlich-Kister polynomials (Eq. 9). Next, two approximate $u^{\mathrm{E}}$ functions were calculated from Eq. 17: the first with $K_{S}^{\mathrm{E}}=0$ and the second with $V^{\mathrm{E}}=0$. An illustration is given in Fig. 5. It is evident that the main contribution to the $u^{\mathrm{E}}$ comes from the excess compression. Moreover, the increase in the excess speed caused by the increase in temperature results entirely from the changes in the excess compression. The contribution from the $V^{\mathrm{E}}$ is independent of temperature. Thus, the positive excess speed has the same origin as the negative excess compression. It is, however, worthy of notice that the speed of sound itself is a concave function of the mole fraction. Its minimum approximately corresponds to the maximum of the excess speed. That have also been observed for the binary mixtures of heptane with 1,2-dibromoethane [7,9] and 1,5-dibromopentane [8,9]. It seems to be a general feature of those systems. 


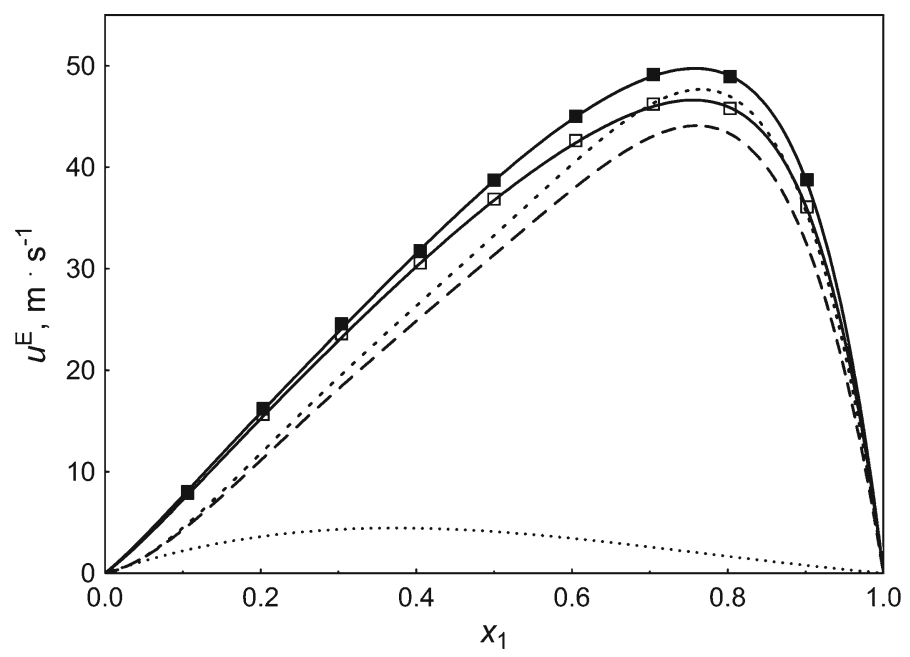

Fig. 5 Excess speed of sound $u^{\mathrm{E}}$ in the dibromomethane (1) + heptane (2) system as a function of the mole fraction: points-experimental results: open square- $293.15 \mathrm{~K}$, filled square-313.15 K; solid linesinterpolation by Eq. 17; broken lines-Eq. 17 with $V^{\mathrm{E}}=0$ (long dash-293.15 K, short dash-313.15 K); dotted line - Eq. 17 with $K_{S}^{\mathrm{E}}=0$ (the lines for $298.15 \mathrm{~K}$ and $313.15 \mathrm{~K}$ overlap one another)

The explanation presented above accounts for the excesses of the molar volume, isobaric expansion, and isentropic compression of dibromomethane + heptane. In spite of the lack of specific interactions in the liquids studied, the molecular picture is rather complicated. It involves both the energetic as well as the steric factors. Although the suggested model is speculative, it is at least probable that a many-body approach is necessary even for a qualitative description of the system properties.

Acknowledgment One of the authors (MCh) is profoundly indebted to Prof. H. Piekarski (University of Łódź) for advice concerning the subject and the measurement technique of heat capacity applied in this study.

Open Access This article is distributed under the terms of the Creative Commons Attribution Noncommercial License which permits any noncommercial use, distribution, and reproduction in any medium, provided the original author(s) and source are credited.

\section{References}

1. Y.S. Hon, T.R. Hsu, C.Y. Chen, Y.H. Lin, F.J. Chang, C.H. Hsieh, P.H. Szu, Tetrahedron 59, 1509 (2003)

2. Y.S. Hon, Y.W. Liu, C.H. Hsieh, Tetrahedron 60, 4837 (2004)

3. Y.S. Hon, C.H. Hsieh, Y.W. Liu, Tetrahedron 61, 2713 (2005)

4. Y.S. Hon, C.H. Hsieh, Tetrahedron 62, 9713 (2006)

5. M.J. Dagani, H.J. Barda, T.J. Benya, D.C. Sanders, Bromine Compounds in Ullmann's Encyclopedia of Industrial Chemistry, vol. A4, 5th edn. (VCH, Weinheim, 1985)

6. S. Ernst, M. Chorążewski, M.B. Tkaczyk, P. Góralski, Fluid Phase Equilib. 174, 33 (2000)

7. M. Chorążewski, J. Chem. Eng. Data 52, 154 (2007)

8. M. Chorążewski, M. Tkaczyk, J. Chem. Eng. Data 51, 1825 (2006)

9. M. Chorążewski, Doctor's Thesis, University of Silesia, Katowice, 2003 
10. B. Orge, M. Iglesias, A. Rodriguez, J.M. Canosa, J. Tojo, Fluid Phase Equilib. 133, 213 (1997)

11. A.M. Postigo, L.J. Zurita, G.L.M. De Soria, M. Katz, Can. J. Chem. 64, 1966 (1986)

12. T.S. Blanco, M.J. Embid, S. Otin, Fluid Phase Equilib. 91, 281 (1993)

13. G. Delmas, P. Purves, J. Chem. Soc. Faraday Trans. 2 73, 1828 (1977)

14. M.J. Embid, M. Artal, J. Fernandez, I. Velasco, S. Otin, J. Chem. Eng. Data 36, 428 (1991)

15. J.-P.E. Grolier, A. Inglese, E. Wilhelm, J. Chem. Thermodyn. 16, 67 (1984)

16. M. Gepert, S. Ernst, J. Solution Chem. 32, 831 (2003)

17. E. Zorębski, M. Zorębski, S. Ernst, Papers of the World Congress on Ultrasonics (Berlin, 1995), pp. $547-550$

18. P. Góralski, M. Tkaczyk, M. Chorążewski, J. Chem. Eng. Data 48, 492 (2003)

19. J.C.R. Reis, A.F.S. Santos, I.M.S. Lampreia, Chem. Phys. Chem. 11, 508 (2010)

20. P. Atkins, J. De Paula, Atkins' Physical Chemistry, chap. 18, 8th edn. (Oxford University Press, Oxford, 2006)

21. J. Garcia, E.R. López, L. Lugo, J. Fernández, Phys. Chem. Chem. Phys. 3, 5006 (2001)

22. P.J. Linstrom, W.G. Mallard (eds.), NIST Chemistry WebBook, NIST Standard Reference Database Number 69 (National Institute of Standards and Technology, Gaithersburg). http://webbook.nist.gov. Retrieved April 7, 2010

23. V. Majer, V. Svoboda, Enthalpies of Vaporization of Organic Compounds: A Critical Review and Data Compilation (Blackwell Scientific Publications, Oxford, 1985), p. 300 in P.J. Linstrom, W.G. Mallard (eds.), NIST Chemistry WebBook, NIST Standard Reference Database Number 69 (National Institute of Standards and Technology, Gaithersburg), http://webbook.nist.gov (Retrieved April 7, 2010)

24. M. Podsiadło, K. Dziubek, M. Szafrański, A. Katrusiak, Acta Cryst. B 62, 1090 (2006)

25. M. Podsiadło, A. Katrusiak, Acta Cryst. B 63, 903 (2007)

26. R. Boese, D. Blaeser, H.-C. Weiss, Angew. Chem. Int. Edit. 38, 988 (1999)

27. D.M. Duffy, P.M. Rodger, Phys. Chem. Chem. Phys. 3, 3580 (2001)

28. Cambridge Crystallographic Data Centre data base, CSD version 5.31, November, 2009

29. S. Blanco, J. Munoz, I. Velasco, S. Otin, J. Chem. Eng. Data 40, 605 (1995)

30. V. Gil-Hernández, P. Garcia-Giménez, S. Otin, M. Artal, I. Velasco, J. Chem. Thermodyn. 37, 7 (2005)

31. P. Garcia-Giménez, V. Gil-Hernández, I. Velasco, J.M. Embid, S. Otin, Int. J. Thermophys. 26, 665 (2005)

32. J. Boquera, M. Artal, I. Velasco, S. Otin, J. Chem. Thermodyn. 30, 161 (1998)

33. V. Griffing, M.A. Cargyle, L. Corvese, D. Eby, J. Phys. Chem. 58, 1054 (1954)

34. V. Rodriguez, C. Lafuente, J. Santafe, F.M. Royo, J.S. Urieta, Fluid Phase Equilib. 108, 185 (1995)

35. TRC Thermodynamics Tables of Non-Hydrocarbons 1994, Thermodynamics Research Center, Texas A\&M University System (College Station, TX)

36. L. Moravkova, J. Linek, J. Chem. Thermodyn. 34, 1387 (2002)

37. J.A. Riddick, W.B. Bunger, Organic Solvents: Physical Properties and Methods of Purification, 3rd edn. (Wiley Interscience, New York, 1970)

38. M. Dzida, P. Góralski, J. Chem. Thermodyn. 38, 962 (2006)

39. O. Dahmani, I. Wichterle, A. Ait-Kaci, Fluid Phase Equilib. 124, 135 (1996)

40. M. Dzida, A. Żak, S. Ernst, J. Chem. Thermodyn. 37, 405 (2005)

41. M. Dzida, W. Marczak, J. Chem. Thermodyn. 37, 826 (2005)

42. M. Dzida, J. Solution Chem. 33, 549 (2004)

43. D.C. Landaverde-Cortes, A. Estrada-Baltazar, G.A. Iglesias-Silva, J. Chem. Eng. Data 52, 1226 (2007)

44. J.M. Pardo, C.A. Tovar, C.A. Cerdeirina, E. Carballo, L. Romani, J. Chem. Thermodyn. 31, 787 (1999)

45. D.R. Lide (ed.), CRC Handbook of Chemistry and Physics, 81st edn. (CRC Press, Boca Raton, FL, 2000)

46. S.G. Lias, Ionization Energy Evaluation, in P.J. Linstrom, W.G. Mallard (eds.), NIST Chemistry WebBook, NIST Standard Reference Database Number 69 (National Institute of Standards and Technology, Gaithersburg), http://webbook.nist.gov (Retrieved April 7, 2010) 